\title{
FeCoNi Nanokristal Toz Alaşımların Yapısal ve Manyetik Özelliklerinin İncelenmesi
}

\author{
Telem Şimşek ${ }^{1 *}$, Tuncay Şimşek ${ }^{2}$, Barış Avar $^{3}$, Şadan Özcan ${ }^{1,4}$ \\ 1* Hacettepe Üniversitesi, Nanoteknoloji ve Nanotıp Anabilim Dalı, Ankara, Türkiye, (ORCID: 0000-0003-4852-2230), telem@ @acettepe.edu.tr \\ ${ }^{2}$ Kırıkkale Üniversitesi, Araçlar ve Ulaştırma Teknolojileri Bölümü, Kırıkkale, Türkiye (ORCID: 0000-0002-4683-0152), tuncaysimsek@kku.edu.tr \\ ${ }^{3}$ Zonguldak Bülent Ecevit Üniversitesi, Metalurji ve Malzeme Mühendisliği Bölümü, Zonguldak, Türkiye (ORCID: 0000-0002-6234-5448), barisavar@ beun.edu.tr \\ ${ }^{4}$ Hacettepe Üniversitesi, Mühendislik Fakültesi, Fizik Mühendisliği Bölümü, Ankara, Türkiye (ORCID: 0000-0001-7966-1845), sadan@ @ hacettepe.edu.tr
}

(International Conference on Design, Research and Development (RDCONF) 2021 - 15-18 December 2021)

(DOI: $10.31590 /$ ejosat.1048336)

ATIF/REFERENCE: Şimşek, T., Şimşek, T., Avar, B. \& Özcan, Ş. (2021). FeCoNi Nanokristal Toz Alaşımların Yapısal ve Manyetik Özelliklerinin İncelenmesi. Avrupa Bilim ve Teknoloji Dergisi, (32), 616-621.

\section{$\ddot{O} \mathbf{z}$}

Bu çalışmada, $(\mathrm{FeCo}) 90 \mathrm{Ni10}$, ( $\mathrm{FeCo}) 70 \mathrm{Ni30}$ ve (FeCo)50Ni50 (\% ağ.) toz alaşımları, 5 saatlik mekanik alaşımla işlemi sonucunda nanokristal yapıda üretilmiştir. Elde edilen alaşımların yapısal ve morfolojik incelemeleri X-ışını kırınım yöntemi (XRD) ve taramalı elektron mikroskobu/ enerji dağılımlı X-1şını spektroskopisi (SEM/EDS) ile analiz edilmiş̧ir. Alaşımların XRD analizi sonucunda yüzey merkezli kübik ve hacim merkezli kübik katı çözelti fazları tespit edilmiştir. (FeCo)90Ni10, (FeCo)70Ni30 ve (FeCo)50Ni50 alaşımlarının kristalit boyutları 5 saatlik öğütme sonucunda sırasıyla 24.7, 23.2 ve $16.5 \mathrm{~nm}$ olarak, örgü gerinimleri ise sırasıyla \% $0.308, \% 0.404$ ve \% 0.563 olarak hesaplanmıştır. Titreşimli Örnek Manyetometresi (VSM) sonuçları, örneklerin düşük koerzivite ve görece yüksek doyum mıknatıslanması ile yumuşak manyetik özelliğe sahip olduğunu göstermektedir. ( $\mathrm{FeCo}$ ) $70 \mathrm{Ni30}$ nanokristal alaşımının sahip olduğu $127 \mathrm{emu} / \mathrm{g}$ değerindeki yüksek doyum mıknatıslanması ve 18 Oe'lik düşük koerzivitesi, alaşımın özelilkle güç üretimi, dağıtımı ve çevrimi gibi yumuşak manyetik özellik gerektiren uygulamalar için iyi bir aday olduğunu göstermektedir.

Anahtar Kelimeler: FeCoNi, Mekanik Alaşımlama, Nanokristal, Manyetik Özellikler.

\section{Investigation of Structural and Magnetic Properties of the FeCoNi Nanocrystalline Powder Alloys}

\begin{abstract}
In this study, $(\mathrm{FeCo})_{90} \mathrm{Ni}_{10},(\mathrm{FeCo})_{70} \mathrm{Ni}_{30}$ ve $(\mathrm{FeCo})_{50} \mathrm{Ni}_{50}(\%$ wt.) nanocrystalline powder alloys are produced by mechanical alloying, where milling duration set for $5 \mathrm{~h}$. The structural and morphological properties of the as-produced alloys are performed using X-ray diffraction (XRD) and scanning electron microscopy/ energy dispersive spectroscopy (SEM/EDS). As a result of the XRD analysis of the alloys, fcc and bcc phases were determined. After $5 \mathrm{~h}$ of milling durations the crystallite sizes lattice strain of the $\left(\mathrm{FeCo}_{90} \mathrm{Ni}_{10}\right.$, $(\mathrm{FeCo})_{70} \mathrm{Ni}_{30}$ ve $(\mathrm{FeCo})_{50} \mathrm{Ni}_{50}$ alloys are calculated as $24.7,23.2$ ve $16.5 \mathrm{~nm}$ and $0.308 \%, 0.404 \%$ ve $0.563 \%$, respectively. Vibrating Sample Magnetometer (VSM) results show that the samples have soft magnetic properties with low coercivity and relatively high saturation magnetization. The high saturation magnetization of $127 \mathrm{emu} / \mathrm{g}$ and low coercivity of $18 \mathrm{Oe}$ of the $\left(\mathrm{FeCo}_{70} \mathrm{Ni}_{30}\right.$ nanocrystalline alloy show that the alloy is a good candidate for applications that require soft magnetic properties, especially for power generation, distribution, and conversion.
\end{abstract}

Keywords: FeCoNi, Mechanical Alloying, Nanocrystalline, Magnetic Properties.

\footnotetext{
* Sorumlu Yazar: telem@hacettepe.edu.tr
} 


\section{Giriş}

Nanokristal yapılı manyetik malzemeler, doyum manyetizasyonu, koerzivite ve Curie Sıcaklığı gibi dikkat çekici özellikleri nedeniyle birçok araştırmanın konusu olmaktadır (Herzer ve ark., 2005; Herzer, 2013; Avar, 2019). Özellikle yüksek manyetik akı yoğunluğu ve geçirgenliğine, hem de düşük koersiviteye sahip olan nanoyapılı yumuşak manyetik malzemeler; otomotiv uygulamaları, ABS sensör halkaları, bilgisayar endüstrisi, transformatörler, jeneratörler, ev aletleri ve ölçüm ekipmanları gibi çeşitli teknolojik uygulamalarda kullanılmaktadır (Herzer ve ark., 2005). Nanokristal malzemelerin yumuşak manyetik özellikleri, amorf alaşımlarda gözlenen özelliklere benzer şekilde, kristalit büyüklügünün manyetokristal değiş-tokuş uzunluğundan daha küçük olmasından kaynaklanır (Herzer, 2013).

Nanoyapılı manyetik malzemeleri; 1sıl buharlaştırma, elektrobiriktirme, gaz yoğunlaşması, hızlı katılaşma, metal plazma reaksiyonu ve mekanik alaşımlama (MA) gibi birçok farklı üretim tekniği ile elde etmek mümkündür. $\mathrm{Bu}$ yöntemler arasında MA tekniği, çeşitli denge ve denge dışı alaşım fazlarının elde edilebildiği kullanışlı bir toz metalurjisi tekniğidir. Bu tekniğin en önemli avantajı, büyük miktarlarda toz malzeme üretilebilmesi ve üretim parametrelerinin kolaylıkla kontrol edilebilmesidir. Bu nedenlerden dolayı MA tekniği, ucuz ve seri üretim gerektiren endüstriyel uygulamalar için uygun bir yöntemdir (Suryanarayana, 2004). MA ile üretilen tüm metalik sistemlerde, artan ögütme süresi ile hem kristalit boyutunun azalması hem de örgü geriniminin artması ortak bir davranıştır. Bununla birlikte, kristalit büyüklüğü nanoboyuta indirildiğinde genel olarak bazı manyetik özellikler geliştirilebilirken, mekanik alaşımlamanın neden olduğu gerilimlerin ve kusurların varlığ manyetik özelliği bozar. Manyetik özellik, çoğunlukla kristalit boyutundaki azalma ile örgü gerinimdeki artışa bağlıdır. Örgü gerinimi, MA ile elde edilen toz malzemelere 1 sıl işlem uygulanarak azaltılabilmekle birlikte, isıl işlem sırasında kristalitler de büyür (Shokrollahi, 2009).

Bilindiği gibi geçiş elementlerinden olan $\mathrm{Fe}, \mathrm{Ni}$ ve $\mathrm{Co}$ elementleri sahip oldukları üstün manyetik özelliklerinden dolayı, literatürde özellikle son yıllarda bu elementlerin birbirleriyle ve farklı elementlerle yapmış oldukları kompozisyonlarından elde edilen çalışmalar göze çarpmaktadır. Jayaraman ve arkadaşları Fe içeriği olarak zengin, yarı-sert manyetik Fe40Co30Ni30 alaşımını mekanik alaşımlama yöntemi ile üretmişlerdir. Fe40Co30Ni30 alaşımının, 300 K'da yarı sert manyetik özellikler sergilediğini, kuvarzivite değerinin yaklaşık olarak $4.30 \mathrm{KA} / \mathrm{m}$ ve doyum manyetizasyonun ise $146.2 \mathrm{Am}^{2} / \mathrm{kg}$ olduğunu hesaplamışlardır (Jayaraman ve ark., 2020). Prasad ve arkadaşları mekanik alaşımlama yöntemi ile Fe-Co-Ni-(Mg-Si)x alaşımını üretmiş, öğütme sonrası numunelerin manyetik ve yapısal analizlerini gerçekleştirmişlerdir. Fe-Co-Ni alaşım sistemine $\mathrm{Si}$ ve $\mathrm{Mg}$ eklenmesiyle tek fazlı yüzey merkezli kübik yapılı malzemeler sentezlediklerini raporlamışlardır (Prasad ve Kumar, 2016). Bir başka çalışmada ise mekanik öğütme atmosferinin, üretilen $\mathrm{Fe}_{40} \mathrm{Co}_{30} \mathrm{Ni}_{30}$ alaşımının manyetik ve yapısal özellikler üzerindeki etkileri araştırılmıştır. 12 saatlik ögütme sonucunda, argon ve asal gaz kullanılmadan gerçekleştirilen deneylerin her ikisinde de çoğunlukla mikron boyutunda ancak nanokristal $\gamma$ fazları da içeren yapı elde ettiklerini belirtmişlerdir. Normal atmosfer koşullarında üretilen örneklerin, argon ortamında üretilen örneklere nispeten daha iyi yar1-sert manyetik özellik gösterdiğini tespit etmişlerdir (Paul ve ark., 2021). Raanaei ve arkadaşları mekanik alaşımlama ile (Co$\mathrm{Ni})_{70} \mathrm{Ti}_{10} \mathrm{~B}_{20}$ alaşımını üretmiş, morfolojik ve manyetik özellikleri belirlemek için çalışmalar yürütmüşlerdir. 190 saatlik öğutme sonucunda amorf ve nanokristalin fazların oluştuğunu belirtmişlerdir. Öğütme sonucunda koerzivite değerinin 39 Oe olduğunu tespit etmişlerdir (Raanaei ve Mohammad-Hosseini, 2016). Bu çalışmada eşit ağırlıklı FeCo içerisine ağırlıkça \%10, 30 ve 50 oranlarında $\mathrm{Ni}$ eklenerek, alaşımların yapısal, morfolojik ve manyetik özellikleri incelenmiştir. Üretilen FeCoNi alaşımları XRD, SEM/EDX ve VSM ile analize edilmiştir.

\section{Materyal ve Metot}

Deneysel çalışmalarda başlangıç malzemeleri olarak elementel Fe (Riedel-de Haen, 99.9\%), Co (Aldrich, 99.9\%), Ni (Aldrich, 99.9\%) tozları kullanılmıştır. Sentez deneyleri gezegensel tip ögütücüde (Fritsch Pulverisette-5) argon atmosferinde gerçekleştirilmiştir. Örnek hazırlama ve numune tartım işlemleri atmosfer kontrollü eldivenli-kutu içerisinde yapılmıştır. Ağırlıkça (FeCo)90Ni10, (FeCo)70Ni30 ve (FeCo)50Ni50 içeren 2'şer gramlık toz numuneler hazırlanmış ve 5 saat öğütülmüştür. Öğütme potası olarak sertleştirilmiş çelik bilyeler ve havan kullanılmıştır. Bilye toz oranı 10:1 ve ögütme hızı $300 \mathrm{rpm}$ olarak sabitlenmiştir. Üretilen tozların faz yapıları, $\mathrm{X}$-ı̧̧ını kırınımı (XRD) (Panalytical Empyrean) yöntemi ile belirlenmiştir. $\mathrm{CuK} \alpha$ 1şıması $(\lambda=1.54 \AA), 45 \mathrm{kV}$ voltaj ve $40 \mathrm{~mA}$ akım ile $2 \theta$ aralığ $20^{\circ}$ 'den $90^{\circ}$ ye kadar $0.013^{\circ}$ adım aralığında ölçümler alınarak yapılmıştır. Sentezlenen alaşımların kristalit boyutları ve örgü gerinimleri, X'Pert High Score yazılımı ile belirlenmiştir. Toz alaşımların morfolojik özellikleri taramalı elektron mikroskobu (SEM) Hitachi SU5000 ile, kompozisyon değişimleri Oxford X-MaxN 80 model enerji dağılımlı X-1şını spektroskopisi (EDS) ile gerçekleştirilmiştir. Örneklerin oda sıcaklığı ve düşük sıcaklık histerisis eğrileri ile sıcaklığa bağlı manyetizasyonlarının değişimi Fiziksel Özellikler Ölçüm Sisteminin (PPMS, Quantum Design) Titreşimli Örnek Manyetometresi (VSM) kullanılarak ölçülmüştür.

\section{Araştırma Sonuçları ve Tartışma}

Şekil 1'de mekanik alaşımlama yöntemi ile farklı stokiyometrilerde üretilen $\mathrm{FeCoNi}$ alaşımları için başlangıç tozları olarak kullanılan $\mathrm{Fe}$, Co ve $\mathrm{Ni}$ elementlerinin XRD deseni verilmiştir. Şekil 1'de ögütme öncesi Fe (Im-3m, ICDD Card No: 87-0721, kübik), Co (P63/mmc, ICDD Card No: 050727, hegzagonal), Ni (Fm-3m, ICDD Card No: 04-0850, kübik) tozlarına ait kristal fazların pikleri görülmektedir. Yapılan incelemelerde, başlangıç tozlarının haricinde herhangi bir kirliliğe ait pike rastlanmamıştır. 


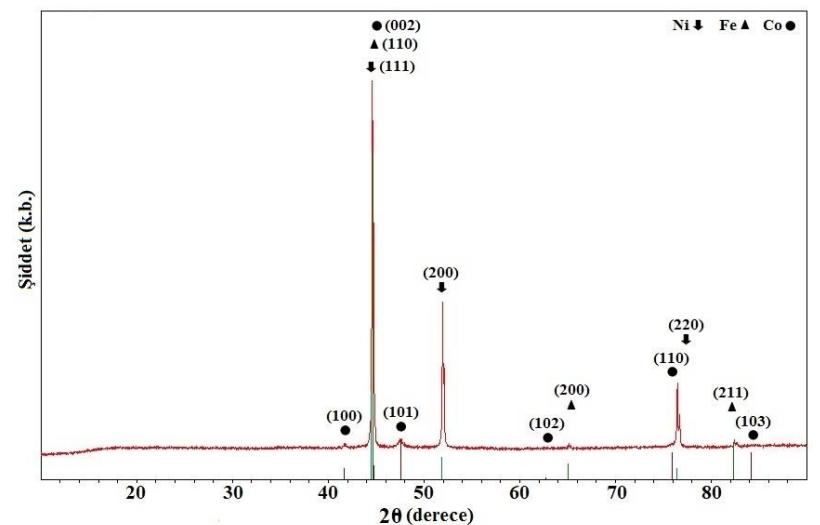

Şekil 1. Elementel Fe, Co ve Ni tozlarına ait XRD grafiği

Sekil 2'de 5 saat süre sonucunda elde edilmis $(\mathrm{FeCo}){ }_{90} \mathrm{Ni}_{10}$, $(\mathrm{FeCo})_{70} \mathrm{Ni}_{30}$ ve $(\mathrm{FeCo})_{50} \mathrm{Ni}_{50}(\%$ ağ. $)$ karışımlarına ait $\mathrm{XRD}$ deseni görülmektedir. $(\mathrm{FeCo}){ }_{90} \mathrm{Ni}_{10}$ alaşımının $\mathrm{XRD}$ deseni incelendiğinde, 5 saat öğütme sonunda başlangıç elementlerine ait piklerin boyunun kısaldığı ve piklerin altında kalan alanların azaldığı görülmektedir. Tek yapılı bir fazın oluşmadığı, Co elementinin $\mathrm{Ni}$ ve $\mathrm{Fe}$ latisleri içerisinde kısmen çözüldüğü görülmektedir. Ni miktarının ağırlıkça \% 30 olduğu deneylerde ise, Co elementinin $\mathrm{Ni}$ ve $\mathrm{Fe}$ latisleri içerisinde daha fazla çözündüğü, hmk ve ymk katı çözelti fazlarının oluştuğu görülmektedir. Fe ve Co elementinin ağırlıkça $\% 25$ 'şer ve $\mathrm{Ni}$ elementinin ağırlıkça \%50 olduğu durumda ise Co'nun $\mathrm{Ni}$ ve $\mathrm{Fe}$ latisi içerisinde tamamen çözündüğü belirlenmiştir. Öğütme sonucunda ortamda hmk ve ymk katı fazlarına ait pikler açıkça görülmektedir. Bilindiği gibi mekanik alaşımlama yönteminde piklerin şiddetinin azalması ve piklerin altındaki alanın genişlemesi öğütülen numunelerin kristalit boyutunda azalmayı ve latis gerinimlerindeki artı̧ı göstermektedir. Bu yöntemde, öğütmenin ilk aşamalarında havan ve bilyeler arasındaki çarpışmalar sonucunda tozlar soğuk kaynaklanmakta, ardından yassılaşmakta ve tekrar kırılmaktadır. Numunelerin parçacık boyutu ilk aşamalarda soğuk kaynaklanma neticesinde agglomerasyon sonucunda artarken, mekanik alaşımlama mekanizmaları neticesinde belli bir aşamadan sonra tozlarda deformasyon sertleşmesi gerçekleşmektekte ve parçacık boyutu daha stabil hale gelmektedir (Suryanarayana, 2004). Şekil 2'deki XRD grafiklerinden başlangıç elementlerinin kristalit boyutu ve latis gerinimi $98.8 \mathrm{~nm}$ ve \% 0.102 olarak hesaplanmıştır. $(\mathrm{FeCo})_{90} \mathrm{Ni}_{10},(\mathrm{FeCo})_{70} \mathrm{Ni}_{30}$ ve $(\mathrm{FeCo})_{50} \mathrm{Ni}_{50}(\%$ ağ. $)$ alaşımlarına ait kristalit boyutları ise sirasıyla $24.7,23.2$ ve $16.5 \mathrm{~nm}$ olarak hesaplanmıştır. Örgü gerinimleri ise $\% 0.308, \% 0.404$ ve $\%$ 0.563 olarak hesaplanmıştır. Elde edilen bulgular, ögüutme ortamında Ni elementinin artmasıla ymk fazın daha baskın hale geldiği ve alaşımların kristalit boyutlarında azalmalar meydana getirdiği tespit edilmiştir. Öğütme süresinin artmasıyla gerçekleşen plastik deformasyon ve elementlerin birbiri içerisinde çözünmesiyle latis gerinimlerinin de arttı̆̆ belirlenmiştir.

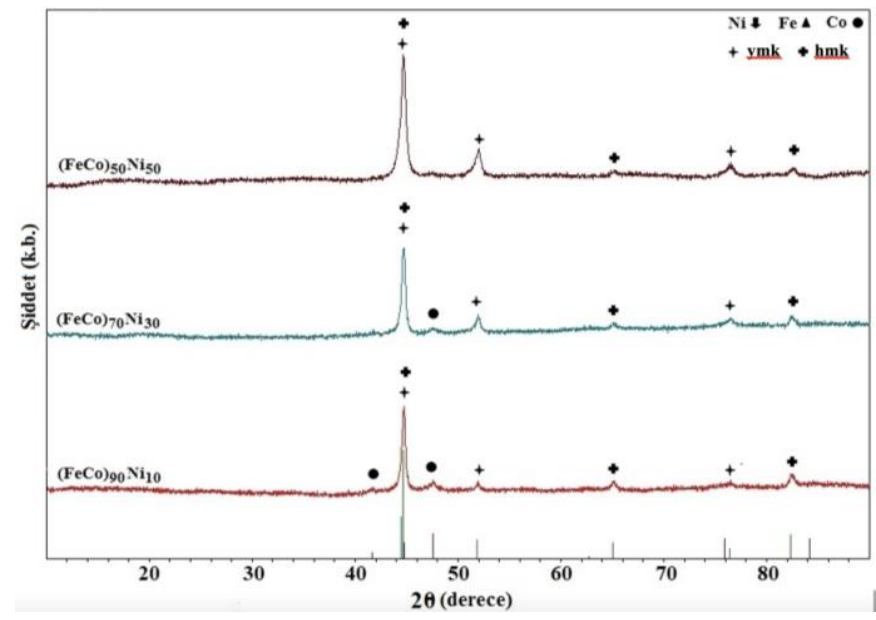

Şekil 2. MA ile üretilen FeCoNi alaşımların XRD grafikleri

MA ile elde edilen Fe-Co-Ni alaşım sistemine ait toz parçacıkların morfolojisi, Şekil 3'te görüldüğü gibi taramalı elektron mikroskobu (SEM) kullanılarak incelendi. Toz parçacıkların SEM görüntülerinden genel olarak, ögütme işlemi sürecini kontrol eden mekanizmalar, parçacıkların şekli ve boyutuyla beraber homojenizasyon ve aglomerasyon davranışları hakkında bilgi sağlanır (Suryanarayana, 2004). Fe-Co-Ni toz parçacıkların 5 saatlik öğütme işlemi süresince, soğuk kaynaklanma ve aglomerasyon mekanizmalarının kırılma mekanizması üzerinde daha baskın halde olduğu anlaşılmaktadır. Dolayısıyla, parçacıkların yüksek yüzey enerjisi nedeniyle plaka benzeri bir morfoloji ve düzensiz şekilli parçacıklar ortaya çıkmıştır. Öğütme işlemi sonucunda parçacıkların katmanlı bir yapıda yaklaşık $20 \mu \mathrm{m}$ 'nin altında geniş boyut dağılımına sahip olduğu görülmektedir.
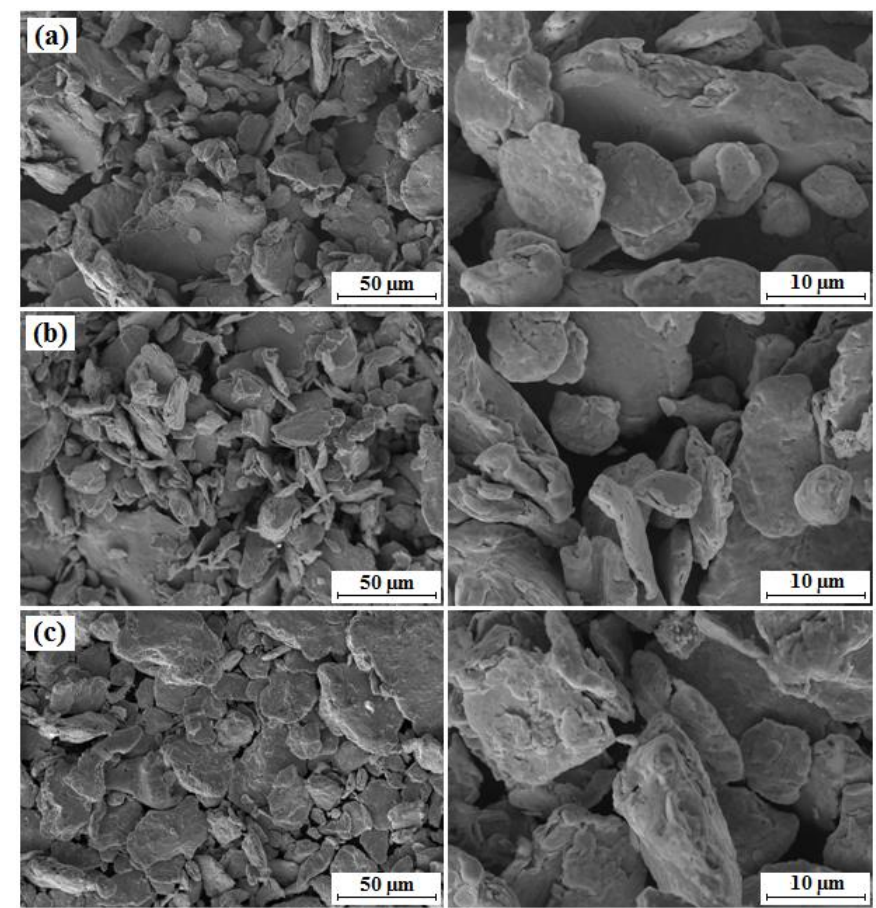

Şekil 3. (a) MA işlemi sonrası elde edilen ( $\mathrm{FeCo})_{90} \mathrm{Ni}_{10},(b)$ $(\mathrm{FeCo})_{70} \mathrm{Ni}_{30}$ ve (c) $(\mathrm{FeCo})_{50} \mathrm{Ni}_{50}$ toz alaşımlarının $1000 \mathrm{X}$ ve $5000 X$ büyütmelerdeki SEM görüntüleri

Şekil 4'te MA işlemi sonrası $(\mathrm{FeCo})_{50} \mathrm{Ni}_{50}$ alaşımının EDS elementel haritalandırma görüntüleri ve spektrumu görülmektedir. Farklı renklerle belirtilen alaşımı oluşturan Fe, $\mathrm{Co}$ ve $\mathrm{Ni}$ elementlerinin birbiri içerisinde homojen olarak 
dağıldığı anlaşılmaktadır. Bununla birlikte MA işlemi süresince toz parçacıkların yüzeyi, öğütme atmosferi ile öğütme haznesi ve bilyelerden kaynaklanan kirliliğe maruz kalabilir. Alaşımların EDS spektrumundan elde edilen elementel bileşim değerlerinin, MA işlemi öncesi belirlenen değerlere yakın olduğu belirlenmiştir.
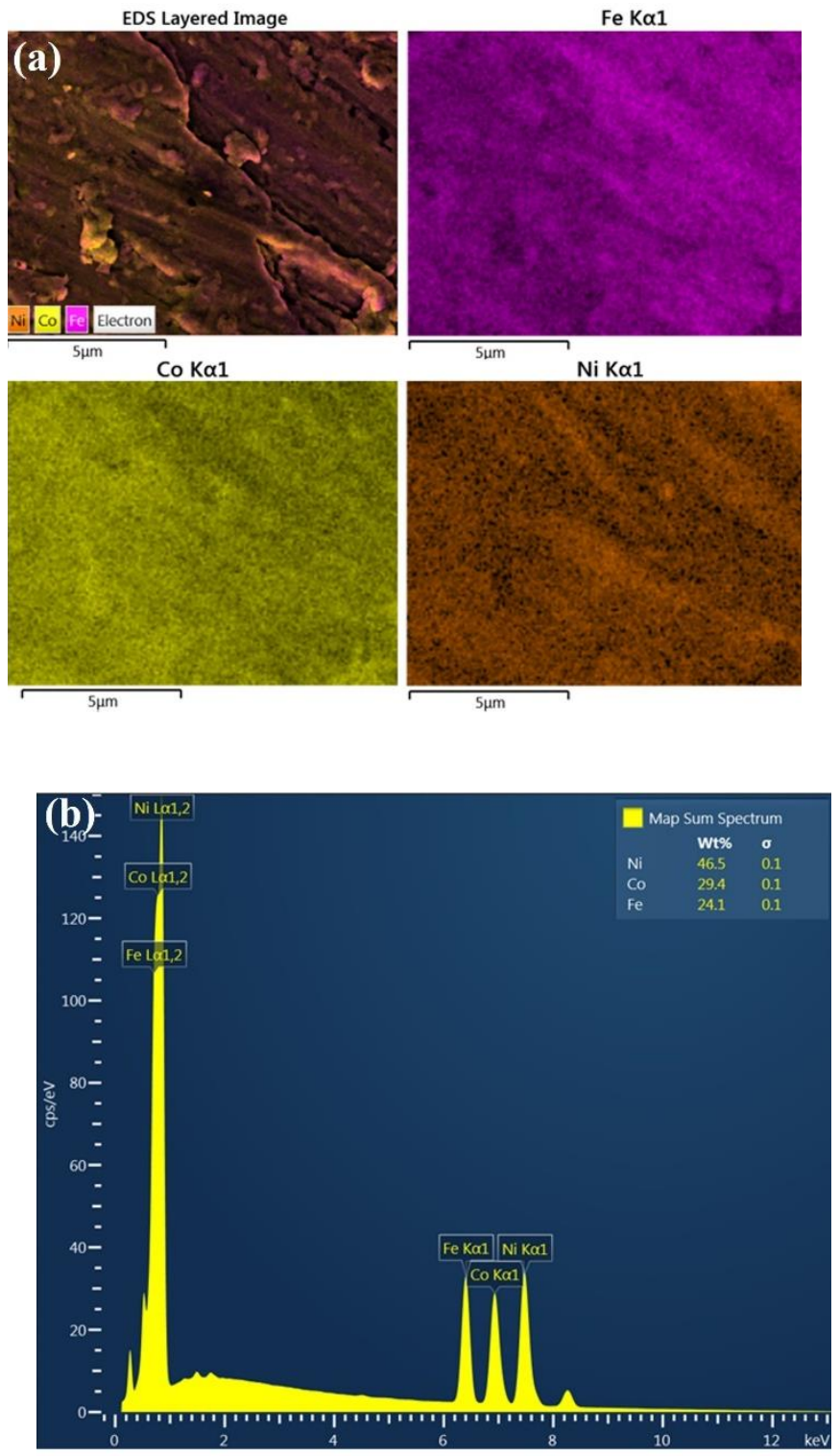

Şekil 4. (FeCo)50Ni50 alaşımının (a) EDS elementel haritalama görüntüleri ve (b) EDS spektrumu

FeCoNi nanokristallerin oda sıcaklığı ve $10 \mathrm{~K}$ 'de ölçülen manyetik alana bağlı manyetizasyon ölçümleri $\mathrm{M}(\mathrm{H})$ eğrileri Şekil 5 a-c'de verilmektedir. Histerisis eğrilerinden elde edilen doyum miknatıslanması (Ms), koerzivite (Hc) ve artık miknatıslanmanın doyum miknatıslanmasına oranı (Mr/Ms) değerleri ise Tablo 1'de özetlenmektedir. Ölçümler genel olarak incelendiğinde, tüm alaşımların ferromanyetik özellik gösterdiği belirlenmiştir. Ek olarak, oda sıcaklığg histerisis eğrilerinden doyum miknatıslanması değerleri $(\mathrm{FeCo})_{50} \mathrm{Ni}_{50},(\mathrm{FeCo})_{70} \mathrm{Ni}_{30}$ ve $(\mathrm{FeCo}){ }_{90} \mathrm{Ni}_{10}$ nanokristal alaşımları için sırasıyla $86.6 \mathrm{emu} / \mathrm{g}$, $127 \mathrm{emu} / \mathrm{g}$ and $117 \mathrm{emu} / \mathrm{g}$ olarak saptanmıştır. $10 \mathrm{~K}$ ve $300 \mathrm{~K}$ sıcaklıklarında ölçülen Ms değerleri karşılaştırıldığında tüm örneklerde düşük sıcaklık doyum değerlerinin daha yüksek olduğu görülmektedir. Bloch yasası ile uyumlu olan bu davranışın nedeni, düşük sıcaklıklarda azalan 1sıl enerjinin manyetik düzenlenimi daha az etkilemesidir (Obaidat ve ark., 2015).

Histerisis eğrilerinden elde edilebilecek diğer bir önemli fiziksel parametre ise koerzivitedir. Üretilen nanokristal alaşımların oda sıcaklığında 18 ila 28 Oe aralığında düşük koerziviteye sahip olup örneklerin yumuşak ferromanyetik özellik gösterdikleri belirlenmiştir. Oda sıcaklığında $127 \mathrm{emu} / \mathrm{g}$ değerindeki yüksek doyum mıknatıslanması ve 18 Oe'lik düşük koerzivitesi ile $(\mathrm{FeCo})_{70} \mathrm{Ni}_{30}$ nanokristal alaşımının güç üretimi, dağıtımı ve çevrimi gibi yumuşak manyetik özellik malzemelerin kullanımını gerektiren uygulamalar için potansiyel vaat ettiği belirlenmiştir. Tablo 1'in son sütununda ise örneklerin $\mathrm{Mr} / \mathrm{Ms}$ oranları özetlenmiştir. Sonuçlar, ögütülmüş tüm alaşımlar için $\mathrm{Mr} / \mathrm{Ms}$ 'nin 0,5'in oldukça altında olduğunu göstermektedir. $\mathrm{Bu}$ sonuç, nanokristal alaşımların çoklu domain yapısını desteklemektedir (Şimşek ve ark., 2021).

Tablo 1. FeCoNi alaşımların $\mathrm{Ms}$, $\mathrm{Hc}$ ve $\mathrm{Mr} / \mathrm{Ms}$ değerleri

\begin{tabular}{|c|c|c|c|c|c|}
\hline Örnek & Ms@300K & Ms@ 10K & Hc@300K & Hc@ 10K & Mr/Ms@300K \\
\hline$(\mathrm{FeCo})_{50} \mathrm{Ni}_{50}$ & 86.6 & 89.6 & 22 & 71 & 0.0240 \\
\hline$(\mathrm{FeCo})_{70} \mathrm{Ni}_{30}$ & 127 & 128 & 18 & 85 & 0,0307 \\
\hline$(\mathrm{FeCo})_{90} \mathrm{Ni}_{10}$ & 117 & 122 & 28 & 103 & 0.0735 \\
\hline
\end{tabular}

Şekil 7'de (FeCo) ${ }_{90} \mathrm{Ni}_{10}$ alaşımının alansız soğutma (zerofield cooled, ZFC) ve alanlı soğutma (field cooled, FC) prosedürleri ile ölçülen sicaklığa bağlı manyetizasyon eğrileri verilmektedir. $\mathrm{Bu}$ ölçümde öncelikle örnek diş manyetik alan uygulanmaksızın oda sıcaklığından düşük sıcaklığa soğutulur. Ardından örneğe diş manyetik alan uygulanarak (bu ölçümde değeri 500 Oe) örnek oda sicaklığına isıtılırken manyetizasyonu ölçülür. Örnek başta alansız soğutulduğundan ölçümün bu basamağı "alansız soğtma, ZFC" olarak adlandırılır. Ardından oda sıcaklığına 1sıtılan örnek alan varlığında tekrar soğutulurken alınan ölçüm ise "alanlı soğutma, FC" olarak adlandırılır. (FeCo) ${ }_{90} \mathrm{Ni}_{10}$ nanokristal alaşımı alansız soğutulduğunda spinleri rastgele düzenlenerek çakılır. Ardından 500 Oe manyetik alan varlığında örnek ısıtılmaya başladığında, artan kT 1sıl enerjisi ile birlikte çakılan spinler alan yönünde yönelebilmeye başlarlar. Bu nedenle artan sicaklık ile birlikte örneğin miknatıslanmasında artış gözlenmektedir. Alanlı 1sıtılan örnek alanlı soğutulduğunda (FC eğrisi) tersinir olmayan bir eğri gözlenir. Bunun nedeni, azalan sicaklıkla birlikte azalan isil enerjinin spinlerin düzenlenimini daha az bozması ve bu nedenle miknatıslanmanın azalan sıcaklıkla artmasıdır. 
(a)

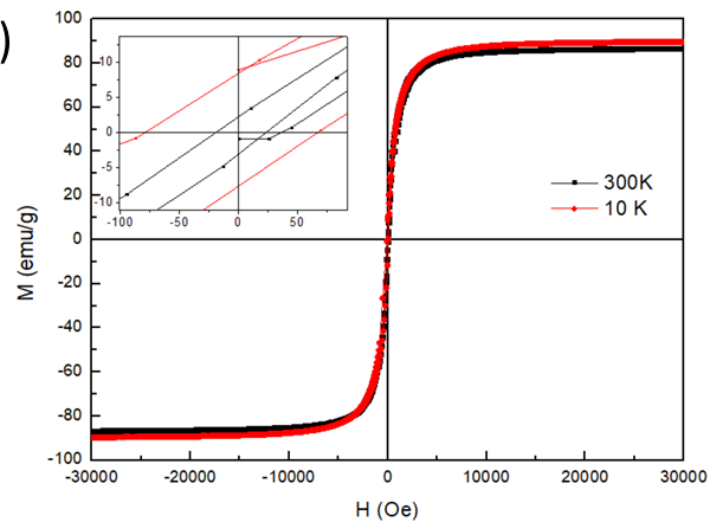

(b)

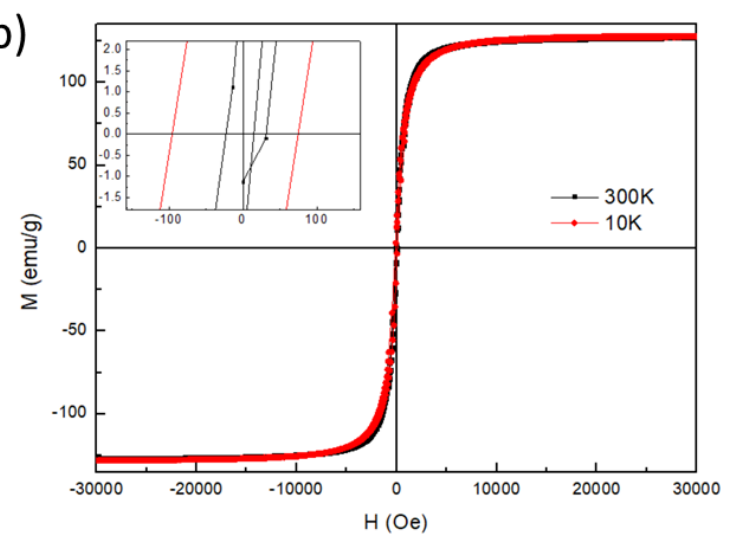

(c)

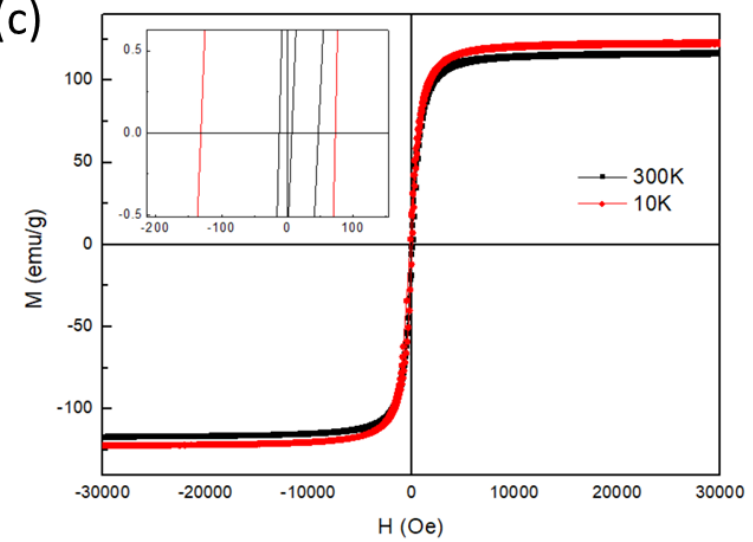

Şekil 6. (a) $(\mathrm{FeCo})_{50} \mathrm{Ni}_{50}$, (b) $(\mathrm{FeCo})_{70} \mathrm{Ni}_{30}$ ve (c) $(\mathrm{FeCo})_{90} \mathrm{Ni} i_{10}$ alaşımlarının $10 \mathrm{~K}$ ve $300 \mathrm{~K}$ sıcaklıklarında ölçülen histerisis ĕgrileri

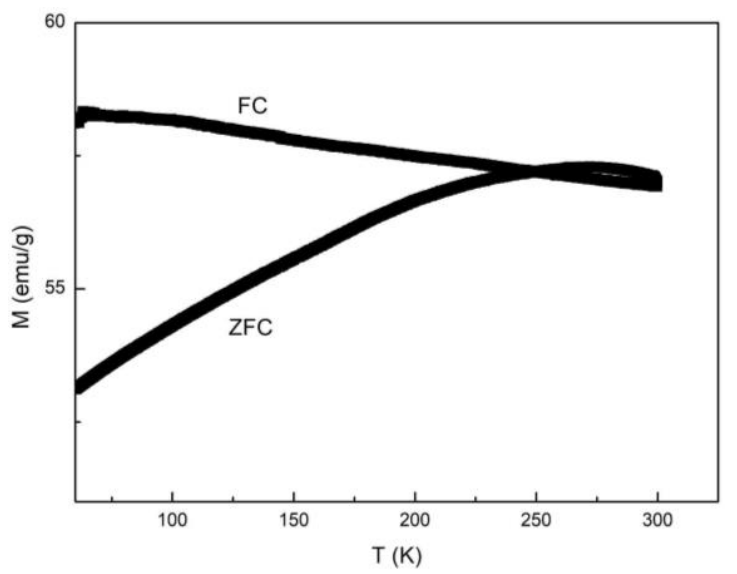

Şekil 7. $(\mathrm{FeCo})_{90} \mathrm{Ni}_{10}$ alaşımının sıcaklı̆̆a bă̆lı manyetizasyon ZFC-FC ĕgrileri

\section{Sonuç}

Yumuşak manyetik özelliklere sahip nanokristal yapılı $(\mathrm{FeCo})_{90} \mathrm{Ni}_{10},(\mathrm{FeCo})_{70} \mathrm{Ni}_{30}$ ve $(\mathrm{FeCo})_{50} \mathrm{Ni}_{50}(\%$ ăg.) alaşımlar1 5 saatlik mekanik alaşımlama işlemi sonrasında elde edilmiştir. Üretilen alaşımların kristalit boyutları $(\mathrm{FeCo})_{90} \mathrm{Ni}_{10}$, $(\mathrm{FeCo})_{70} \mathrm{Ni}_{30}$ ve $(\mathrm{FeCo})_{50} \mathrm{Ni}_{50}$ (\%ağ.) alaşımlarına için sırasıyla 24.7, 23.2 ve $16.5 \mathrm{~nm}$ olarak bulunmuştur. Alaşım sisteminde $\mathrm{Ni}$ içeriğinin artmasıyla latis gerinimlerinin arttı̆̆ belirlenmiştir. Nanokristal alaşımların SEM analizlerinden, toz parçacıkların düzensiz ve tabakalı bir morfolojide olduğu görüldü. Alaşımların EDS analizlerinden ise, yapıyı oluşturan elementlerin birbiri içerisinde homojen olarak dağıldığı ve öğütücü hazne ve bilyelerden kaynaklanabilecek safsızlığın oluşmadığı anlaşıldı. Üretilen nanokristal alaşımların yumuşak ferromanyetik özellik gösterdiği saptandı. Örneklerin doyum mıknatıslanması ve koerzivite değerleri karşılaştırıldığında, oda sıcaklığında sahip olduğu 18 Oe değerindeki düşük koerzivitesi ve $127 \mathrm{emu} / \mathrm{g}$ değerindeki yüksek doyum mıknatıslanmasi ile $(\mathrm{FeCo})_{70} \mathrm{Ni}_{30}$ nanokristal alaşımının, yumuşak manyetik malzemelere gereksinim duyulan enerji gibi sektörlerde verimli şekilde kullanılabileceği saptandı.

\section{Teșekkür}

$\mathrm{Bu}$ çalışma Zonguldak Bülent Ecevit Üniversitesi BAP 2015-73338635-01 nolu proje ile desteklenmiştir.

\section{Kaynakça}

Avar, B. (2019). Nanokristal Co70Si15B15 Toz Alaşımların Yap1sal, Termal ve Manyetik Özelliklerinin İncelenmesi. Süleyman Demirel Üniversitesi Fen Bilimleri Enstitüsü Dergisi, 23(1), 83-89.

Herzer, G., Vazquez, M., Knobel, M., Zhukov, A., Reininger, T., Davies, H. A., ... \& Ll, J. S. (2005). Round table discussion: Present and future applications of nanocrystalline magnetic materials. Journal of magnetism and magnetic materials, 294(2), 252-266.

Herzer, G. (2013). Modern soft magnets: Amorphous and nanocrystalline materials. Acta Materialia, 61(3), 718-734.

Jayaraman, T. V., Rathi, A., \& Thotakura, G. V. (2020). Evaluation of the suitability of Fe40Co30Ni30 as a precursor for Fe-rich FeCoNi-based high-entropy semi-hard magnets. Intermetallics, 119, 106715.

Obaidat, I. M., Issa, B., Albiss, B. A., \& Haik, Y. (2015, August). Temperature dependence of saturation magnetization and coercivity in $\mathrm{Mn} 0.5 \mathrm{Zn} 0.5 \mathrm{Gd} 0$. 02Fe1. $98 \mathrm{O} 4$ ferrite nanoparticles. In IOP Conference Series: Materials Science and Engineering (Vol. 92, No. 1, p. 012012). IOP Publishing.

Prasad, N. K., \& Kumar, V. (2016). Structure-magnetic properties correlation in mechanically alloyed nanocrystalline $\mathrm{Fe}-\mathrm{Co}-\mathrm{Ni}-(\mathrm{Mg}-\mathrm{Si}) \quad \mathrm{x}$ alloy powders. Journal of Materials Science: Materials in Electronics, 27(10), 10136-10146.

Paul, A. A., Rathi, A., Thotakura, G. V., \& Jayaraman, T. V. (2021). Influence of milling atmosphere on the structure and magnetic properties of mechanically alloyed 
Fe40Co30Ni30. Materials Chemistry and Physics, 258, 123897.

Raanaei, H., \& Mohammad-Hosseini, V. (2016). Morphology and magnetic behavior of cobalt rich amorphous/nanocrystalline (Co-Ni) 70Ti10B20 alloyed powders. Journal of Magnetism and Magnetic Materials, 414, 90-96.

Suryanarayana, C. (2004). Mechanical alloying and milling. Marcel Dekker Inc.

Shokrollahi, H. (2009). The magnetic and structural properties of the most important alloys of iron produced by mechanical alloying. Materials \& Design, 30(9), 3374-3387.

Şimşek, T., Avar, B., Şimşek, T., Yıldız, B., Chattopadhyay, A. K., \& Özcan, Ş. (2021). A Single Step Synthesis By Mechanical Alloying and Characterization of Nanostructured Fe2B of High Magnetic Moment. Ceramics International. 